\title{
Un episodio sangriento en Palma y López Albújar
}

Por Dora Bazán 
Doctora en Educación, Filología, Filología Románica, Lingüística y Literatura. Profesora emérita de la UNMSM y directora del Instituto de Estudios Clásicos y Orientales de la URP. 
El asunto del cual nos ocuparemos trata de una parte específica de la tradición "La emplazada" y de la novela "Matalaché" de López Albújar.

"La emplazada" de Ricardo Palma es una de sus tradiciones no históricas, tal como se descubre en los contextos, en el tratamiento de los personajes y en el uso de los instrumentos literarios que utiliza siempre para escribir este tipo de relatos:

Confieso que, entre las muchas tradiciones que he sacado a luz, ninguna me ha puesto en mayores atrenzos que la que hoy traslado al papel. La tinta se me vuelve borra entre los puntos de la pluma, tanto es de espinoso y delicado el argumento. Pero a Roma por todo, y quiera un buen numen sacarme airoso de la empresa, y que alcance a cubrir con un velo de decoro, siquiera no sea muy tupido, este mi verídico relato de un suceso que fue en Lima más sonado que las narices. ${ }^{1}$

Lo anterior es reafirmado por el mismo autor de la tradición, ya que es evidente el ahistoricismo que aparece cuando escribe:

Y perdóname, lector, que altere nombres y que no determine el lugar de la acción, pues, al hacerlo, te pondría los puntos sobre las íes, y acaso tu malicia te haría sin muchos tropezones señalar con el dedo a los descendientes de la condesa de Puntos suspensivos,

I Ricardo Palma. Tradiciones Peruanas Completas, Aguilar 1964, pág. 470. 
como hemos convenido en llamar a la interesante viuda. En materia de guardar un secreto, soy canciller del sello de la Puridad. ${ }^{2}$

Sin embargo, y pese a las diferencias de género literario existentes entre las obras que analizamos -el género Tradición creado por Ricardo Palma, y el género novela-hemos encontrado que Matalaché es la tradicional novela decimonónica con un autor omnisciente que se ocupa de analizar los sentimientos, pensamientos y pasiones de sus personajes e interviene expresando claramente sus propias opiniones.

Lo mismo sucede con Palma, que utiliza al autor omnisciente y cuyos contextos, personajes y circunstancias del episodio final son prueba fehaciente de lo que afirmamos.

\section{CONTEXTOS:}

\section{I Contexto Temporal}

\subsubsection{En La Emplazada}

Ricardo Palma explícitamente señala que la tradición "La Emplazada" ocurrió en 1688. Más aún, anota como subtítulo que su crónica corresponde a la época del Virrey Arzobispo. En palabras de Palma, "Doña Verónica Aristizábal, no embargante sus cuarenta pascuas floridas, era por los años de 1688 lo que en toda tierra de herejes y cristianos se llama una buena moza. Jamón mejor conservado, ni en Westfalia,...." ${ }^{3}$ Lo curioso de esta referencia es que el episodio relatado pertenece al siglo XVII, mientras que Palma nació en el siglo XIX. Sin embargo,

2 Op. cit., pág., 471, 472.

3 Op. cit., pág. 470. 
y como acostumbra, se hizo contemporáneo de la protagonista tal como lo señala al inicio de la tradición que comentamos.

Para más abundar, debo anotar que, en su acostumbrado parrafillo histórico, Palma desarrolla algunas ocurrencias de la época del Virrey Arzobispo, anotando el estado económico del virreinato que le entregó su antecesor, sino también los sucesos ocurridos en Buenos Aires y en Panamá con los filibusteros; sin dejar de hacer sus graciosas anotaciones a asuntos de conventos y a la publicación de libros realizados en Madrid. Reproducimos dos citas de Palma, la que se refiere a los filibusteros y la que alude a Buenos Aires, porque López Albújar hizo referencias semejantes, suprimiendo las referidas a los conventos y a la publicación de libros por razones históricas. ${ }^{4}$

\subsubsection{En Matalache}

El contexto temporal en Matalaché se encuentra explícitamente anotado en el capítulo referido a La Tina, cuando el autor escribe lo siguiente: "La Tina era en 1816..." . Esta referencia no es del todo exacta, puesto que la alusión se debe a que el caserón fue heredado por Don Juan Francisco al ser nieto del licenciado Don Cosme de los Ríos, que fue su fundador: "un hidalgo industrioso del siglo XVIII"6

Otra referencia al contexto histórico aparece en el diálogo entre don Baltazar y el padre de María Luz, en donde hablan de los filibusteros de una época anterior a la que se refiere Palma ${ }^{7}$.

4 Op. Cit., pág. 472.

5 Enrique López Albújar. Matalaché. Bogotá, 1996, pág. 20.

6 Op. Cit., pág. 23.

7 Ibídem, pág. 13. 


\subsection{Contexto Situacional}

\subsubsection{En La Emplazada}

Respecto al contexto situacional de "La Emplazada", debo anotar que se da en dos lugares. El primero de ellos aparece al iniciar la tradición, cuando Palma anota que es "este mi verídico relato de un suceso que fue en Lima más sonado que las narices"8. Ella vivía en la ciudad con su familia, el conde de Puntos Suspensivos, dos hijos y la gente que le servía. Es fácil deducir lo anterior, pese a que Palma no lo señala explícitamente, pues lo hace a través del parrafillo histórico, en la detallada descripción de la llegada del Virrey Arzobispo, contemporáneo suyo.

El otro contexto situacional es el de la hacienda donde va a vivir después de enviudar. Hablando de la herencia dejada por el conde y que: "consistía, amén de la casa solariega y valiosas propiedades urbanas, en dos magníficas haciendas situadas en uno de los fertilísimos valles próximos a esta ciudad de los reyes"9. Este contexto no aparece descrito y solo se refiere a que "luego que pasaron los primeros meses de luto y que hubo llenado fórmulas de etiqueta social, abandonó Verónica la casa de Lima, y fue con baúles y petacas a establecerse en una de las haciendas. Para que el lector se forme concepto de la importancia del feudo rústico, nos bastará consignar que el número de esclavos llegaba a mil doscientos." ${ }^{10}$

8 Palma, Op. Cit., pág. 470.

9 Ibídem.

10 Ibíd. Pág. 471. 


\subsubsection{En Matalache}

En cuanto al contexto situacional debo anotar que la descripción del lugar de los hechos es muy detallada. Esto no solo por tratarse de una novela sino por la importancia que tiene este contexto en los personajes y en la ocurrencia de los hechos. López Albújar anota que el inmigrante abuelo de Don Juan Francisco, padre de la protagonista María Luz, no hizo ningún arreglo en La Tina sino que "recibió la Tina cayendo entre las cuatro paredes de la maltrecha fábrica" 11

Aún así, La Tina mereció una descripción muy detallada: "La Tina era en 1816 un caserón de adobe, ladrillo y paja, levantado a sotavento de la ciudad, unos quinientos pasos más allá de su extremo norte, besando la escarpada margen derecha del Piura y sobre una prominencia del terreno. Vista de lejos, semejaba de día, por su aislamiento y extensión, un castillo feudal, y en las noches, un aguafuerte goyesco". ${ }^{12}$

\subsection{Contexto Sociocultural}

\subsection{En La Emplazada}

Ricardo Palma empieza hablando de la fortuna que el conde dejó a su viuda: "La fortuna del conde era lo que se dice señora fortuna, y consistía, amén de la casa solariega y valiosas propiedades urbanas, en dos magníficas haciendas situadas

11 López Albújar, Op. cit., pág. 23.

12 Op. cit., pág. 20. 
en uno de los fertilísimos valles próximos a esta ciudad de los reyes."13

Sin insistir mayormente en la personificación ni la reiteración adjetival presente a través de las frases "valiosas propiedades urbanas", "magníficas haciendas" y "fertilísimos valles", queremos aludir a la referencia que Palma hace acerca de que: "Luego que pasaron los primeros meses de luto y que hubo llenado fórmulas de etiqueta social, abandonó Verónica la casa de Lima, y fue con baúles y petacas a establecerse en una de las haciendas. Para que el lector se forme concepto de la importancia del feudo rústico nos bastará consignar que el número de esclavos llegaba a mil doscientos." ${ }^{4}$

Cabe anotar la semejanza que existe en cuanto a la población negra sobre la que escribirá Enrique López Albújar, destacando el número de esclavos con que contaba: "junto con el traspaso se le dio una docena y media de esclavos, viejos en su mayor parte, dos de ellos medio bozales y sin cristianar, y al frente de este rebaño a un mulato...."15.

\subsubsection{En Matalache}

El contexto sociocultural en Matalaché es el de la esclavitud, en unos niveles que pocas obras literarias en el mundo han descrito pues la degradación llegó hasta convertir realmente en bestias a los seres humanos ya que "Matalaché" llegó a servir en un determinado momento como un semental.

13 Ricardo Palma, Op. cit., pág. 470.

14 Op. cit., pág. 471.

15 López Albújar, Op. cit., pág. 23. 


\section{PERSONAJES}

\subsection{Personajes Protagónicos}

\section{I.I En La Emplazada}

La protagonista de "La Emplazada" es descrita por Palma, usando la figura de la sinestesia gustativa, tal como acostumbra hacerlo en sus prosopografías, y que ahora volvemos a citar: “Doña Verónica Aristizábal, no embargante sus cuarenta pascuas floridas era por los años 1688 lo que en toda tierra de herejes y cristianos se llama una buena moza. Jamón mejor conservado ni en Westfalia."16

Aparte de lo anteriormente anotado es importante señalar que, en el retrato de la protagonista, se destacan su nombre, su apellido de origen vasco y su edad, pues, para Palma, esta tiene gran significación porque es un dato fundamental y por eso habla de sus "cuarenta pascuas floridas", que contrastan con los "veinticuatro años" del mulato y, sobre todo, con los "quince a diez y seis abriles" de Gertrudis.

\subsubsection{En Matalache}

Matalaché es el protagonista sine quanon de la obra que lleva su nombre y que es descrito por López Albújar de la siguiente manera: "Física y espiritualmente José Manuel era el negro menos negro de los esclavos de La Tina. Su tipo, su porte, cierto espíritu de orden e iniciativa y un marcado sentimiento de altivez diferenciábale grandemente de la negrada, hasta el punto de despertar en ellos, especialmente

16 Palma, Op. cit., pág. 470. 
en congos y carabalíes, antipatías y animosidades rayanas en el odio. Al compararse ellos con José Manuel descubrían en los rasgos fisonómicos de este el sello inconfundible de la blanca intromisión del cruzamiento, al que, no obstante envidiárselo, consideraban como un agravio y una traición, que no quisieron perdonarle nunca. La oculta soberbia de su raza les hacía ver en este mestizo, engendrado seguramente en una hora de vandalismo sexual, tránsfuga, cuya falta se encargaba su rostro mismo de pregonar."17

A semejanza de Palma, la descripción de Matalaché al igual que la de Pantaleón alude a sus habilidades manuales que son descritas por ambos autores ${ }^{18}$.

\subsection{Personajes Secundarios}

\subsubsection{En Palma}

En la tradición "La Emplazada" existen varios personajes secundarios: el conde, esposo de la protagonista; sus dos hijos, el mayordomo, el administrador, un sacerdote y dos esclavos; Pantaleón y Gertrudis.

La importancia de estos personajes es muy diferente y notoria. Y esto es expresado por Palma a través de diversos instrumentos estilísticos. El primero de ellos se refiere al nombre propio, como bien lo hemos demostrado en nuestro libro "Los Nombres en Palma".

17 López Albújar, Op. cit., pág. 59.

18 Confróntense las páginas 471 en Palma y el capítulo titulado Unos pies divinos y unas manos hábiles”, López Albújar, op. Cit., pág. 80 y siguientes. 
En contraste con la descripción anterior surge la prosopografía referente a Pantaleón, quien es descrito de la siguiente manera: "había entre ellos un robusto y agraciado mulato, de veinticuatro años"19. Palma añade párrafos después que "Pantaleón no solo gozaba del prestigio que da la ciencia sino que su cortesanía, su juventud y su vigorosa belleza física formaban contraste con la vulgaridad y aspecto del mercedario y los gallegos". ${ }^{20}$

En cuanto al esposo de Verónica, este no posee un nombre propio y solo tiene un quasi apodo referido a su título "Conde de Puntos Suspensivos" respecto al que Palma, en su especial estilo, señala que "es un título como otro cualquiera, pues el real no se me antoja ponerlo en letras de molde". ${ }^{21}$

Lo digno de destacar de la anterior descripción no solo se refiere a la ausencia de nombre y a la forma de tratamiento referida a él sino que la lectura interlineal nos puede permitir descubrir sugerencias que están abiertas a la imaginación de un lector acucioso, como se muestra en la referencia a: "La fortuna del conde era lo que se dice señora fortuna, y consistía, amén de la casa solariega y valiosas propiedades urbanas, en dos magníficas haciendas situadas en uno de los fertilísimos valles próximos a esta ciudad de los reyes." 22

Los otros personajes secundarios carecen de nombre propio: los hijos de Verónica que -deduzco- los dejó en la ciudad para que estudien; a cargo de instructores asalariados, el mayordomo, el administrador y el sacerdote, de quienes se anota lo siguiente: “... en la mesa donde comían el mayordomo, el administrador, gallego burdo como un alcornoque, el primer caporal, que era otro ídem fundido en el mismo molde, y el capellán, rechoncho

19 Ricardo Palma, Op. Cit., pág. 471.

20 Op. Cit., pág. 471.

21 Palma, Op. cit., pág. 470.

22 Op. cit., pág. 470 
fraile mercedario y con más cerviguillo que un berrendo de Bujama". ${ }^{23}$

Y no solo se trata de diferencias en cuanto al nombre sino también a los aspectos prosopográficos y etopéyicos que aluden a la convivencia con Pantaleón, en primer lugar a: "Estos, aunque no sin murmurar por bajo, tuvieron que aceptar por comensal al flamante doctor; y en breve, ya fuese por la utilidad de servicios que este les prestara librándolos en más de un atracón, o porque se les hizo simpático por la agudeza de su ingenio y distinción de modales, ello es que el capellán, mayordomo y caporal no podían pasar sin la sociedad del esclavo, a quien trataban como a íntimo amigo y de igual a igual." ${ }^{4}$

Respecto a la cita anterior, es necesario referirse a las diferencias diacrónicas del lenguaje empleado por Palma: cerviguillo es un diminutivo despectivo que alude a la cerviz, y berrendo es un sinónimo de un toro de Bujama, ciudad cercana a Mala, perteneciente a la provincia de Cañete, departamento de Lima; famosa en los tiempos de Palma por la cría de toros de lidia. Más aun, la relación de antipatía hacia el clero que Palma revela a lo largo de sus tradiciones, se expresa en este caso en la adjetivación que usa para referirse al capellán de la hacienda. Emplea el adjetivo "rechoncho", que alude al pecado de la gula que señala como una característica propia del clero que vivía cerca a las personas con poder político y económico tal como ocurre en otra de sus tradiciones: "Beba Padre, que le da la vida". Y en la selección que hace de la palabra cerviguillo que aparece como parte de una comparación: "más cerviguillo, que un berrento de Bujama", y que constituye el llamado tertium comparationes aludido al pecado de soberbia que atribuye al capellán.

23 Op. cit., pág. 471.

24 Op. cit., pág. 471. 
Otro personaje importante es Gertrudis, de quien se dice lo siguiente: "hizo salir de un convento de monjas de Lima a una esclavita, de quince a diez y seis abriles, fresca como un sorbete, traviesa como un duende, alegre como una misa de aguinaldo y con un par de ojos negros, tan negros, que parecían hechos de tinieblas. Era la predilecta, la engreída de Verónica." ${ }^{25}$

En un rapto de falsa modestia Palma anota lo siguiente: "Describir la belleza de Gertrudis sería para mí obra de romanos. Pálido sería el retrato que emprendiera yo hacer de la mulata, y basta que el lector se imagine uno de esos tipos de azúcar refinada y canela de Ceylán...”. ${ }^{26}$

Finalmente no solo se trata de la prosopografía sino de la etopeya con la que describe a Gertrudis señalando lo siguiente: "Y la muchacha aprovechó también las lecciones, que no había en Lima más diestra tañedora de arpa, ni timbre de voz más puro y flexible para cantar la bella Aminta y el pastor feliz, ni pies más ágiles para trenzar una sajuriana, ni una cintura más cenceña y revolucionaria para bailar un bailecito de la tierra." ${ }^{27}$

Los otros personajes secundarios son un sacerdote y el mayordomo o administrador de la hacienda. Respecto a ellos, Palma dice lo siguiente: "Mayordomo o administrador, gallego burdo como un alcornoque, el primer caporal, que era otro ídem fundido en el mismo molde, y el capellán, rechoncho fraile mercedario y con más cerviguillo que un berrendo de Bujama". ${ }^{28}$

25 Ibídem, pág. 473.

26 Ibídem.

27 Ibíd.

28 Palma, op. Cit., pág. 471. 
Para más abundar es necesario transcribir otra cita de Palma con el objeto de destacar lo mismo que venimos señalando: "Estos, (los allegados) aunque no sin murmurar por bajo, tuvieron que aceptar por comensal al flamante doctor: y en breve, ya fuese por la utilidad de servicios que este les prestara librándolos en más de un atracón, o porque se les hizo simpático por la agudeza de su ingenio y distinción de modales, ello es que el capellán, mayordomo y caporal no podían pasar sin la sociedad del esclavo, a quien trataban como a íntimo amigo y de igual a igual." 29

\subsubsection{En Matalache}

El principal personaje secundario en Matalaché es María Luz, de quien se hace una somera descripción física y abundan la referencias al efecto positivo que tuvo la presencia de la hija del dueño de la hacienda, tan importante que le dedica un capítulo de su novela al que tituló "El Milagro de María Luz"30

Existen otros personajes secundarios en Matalaché de los cuales queremos destacar, sobre todo, al padre de María Luz, a la esclava Casilda que la apoyó en sus amores con Matalaché y a la esclava anciana que había sido su ama de llaves y que es otro personaje adyuvante de la novela que comentamos. Con el objeto de no alargar esta exposición, no nos vamos a referir a Juan Francisco, el padre de María Luz, antes del episodio final; únicamente haremos referencia a él en el siguiente capítulo.

29 Op. cit., pág. 471.

30 López Albújar, op. Cit., pág. 52 y siguientes. 


\section{UN EPISODIO SANGRIENTO EN PALMA Y LOPEZ ALBUJAR}

\subsection{Antecedentes}

\subsection{En Palma}

Debemos destacar que Ricardo Palma ofrece en su tradición "La Emplazada" como antecedentes del episodio que constituye la cala de nuestro análisis, la cercanía y familiaridad entre Pantaleón y la viuda y que dio lugar a que ella se enamorase del esclavo ${ }^{31}$.

El ocio es otro de los antecedentes del clímax en "La Emplazada": "Verónica era mujer, y con eso está dicho que su imaginación debía dar mayores proporciones al contraste. El ocio y aislamiento de vida en una hacienda, los nervios siempre impresionables en las hijas de Eva." ${ }^{2}$

Otro antecedente lo constituye la esclavita negra Gertrudis. ${ }^{33}$

El último antecedente, y el principal, son los celos del mercedario y de la propia Verónica que se convierten en lo que será el estímulo directo del final atroz.

\subsubsection{En Matalache}

Los antecedentes del episodio sangriento objeto del capítulo final de la novela que lleva el revelador título de "El Último

31 Palma, op. Cit., pág. 471.

32 Palma, Op. cit., pág. 471.

33 Op. cit., pág. 473. 
Jabón de la Tina”, lo constituyen los amores surgidos entre María de la Luz, hija del dueño de la tina, y José Manuel "Matalaché", esclavo mulato. Al lado de ellos están: el aburrimiento, la molicie, el efecto del sol piurano y sobre todo, la relación de los protagonistas.

- Aburrimiento y molicie:

Cuando María Luz llegó a Piura, aparentaba un estado de ánimo que fue descrito por López Albújar con destacada maestría. ${ }^{34}$

Ella en realidad, conforme lo anota el autor en el texto anterior, se encontraba aburrida y no solo sufría los efectos del sol piurano ${ }^{35}$.

Respecto a la molicie, debemos anotar que López Albújar dedica un capítulo completo a la siesta. ${ }^{36}$

- El amor de los protagonistas

- El primer encuentro

El primer encuentro -lo podemos señalar- no fue real sino primero visual. ${ }^{37}$

Posteriormente María Luz expresa su deseo de visitar las posesiones de su padre, lo cual aparece narrado en el capítulo titulado "Un paseo por la fábrica"38.

Posteriormente, un segundo encuentro ocurre cuando José Manuel se ofrece para prestarle un servicio de acuerdo con

34 López Albújar, Op. cit., pág. 27.

35 Op. Cit., pág. 30 y siguientes.

36 Op. cit., pág. 43 y siguientes.

37 Op. cit., pág. 33.

38 Op. Cit., pág. 36 y siguientes. 
sus habilidades manuales: "Si la señorita quisiera, le haría unas zapatillas para la casa o unos chapines para la calle, que harían hablar de sus pies lo menos un año." ${ }^{2}$ A continuación se establece un diálogo más cercano que remarca el acercamiento entre los protagonistas" $"$.

\subsection{Climax de la acción final}

\subsection{En La Emplazada}

La soledad de Verónica, expresada en la ausencia de un consejero o de un confidente, hizo que ella perdiera el equilibrio psicológico al punto que se dejó dominar por sus pasiones, por la obnubilación de su inteligencia que dejó de controlar sus acciones. Dice Palma al respecto: "Una hora después, Verónica, afectando serenidad de espíritu, se dirigió al trapiche e hizo llamar al médico. Pantaleón se presentó en el acto, creyendo que se trataba de asistir a algún enfermo". ${ }^{41}$

En cuanto al comportamiento de Pantaleón, es interesante observar que él no delató a Gertrudis. En palabras de Palma: "La energía del infortunado Pantaleón no se desmintió ante la

feroz amenaza, y abandonando el aire respetuoso con que hasta ese instante había contestado a las preguntas de su ama." ${ }^{n 2}$

El clímax del episodio que comentamos se encuentra al final del tercer capitulillo ya que el cuarto trata de otro tema que no es el de la cala que analizamos: "-iInsolente! Gritó furiosa la

39 Op. cit., pág. 89.

40 Ibíd.

41 Palma, op. Cit., pág. 474.

42 Op. Cit., pág. 474. 
condesa, cruzando con su chicotillo el rostro del infeliz-. iA la paila! iA la paila con él!, iHorrori Y el horrible mandato quedó cumplido en el instante. ${ }^{43}$

\subsubsection{En Matalache}

El episodio final que marca el clímax de la novela empieza nuevamente con el empleo de la descripción que tan bien maneja López Albújar, quien, en realidad pinta la deshumanización que se opera en Juan Francisco, el padre de María Luz: "Don Juan, ¿va usted a hacer jabón conmigo? Si es así, que le sirva para lavarse la mancha que le va a caer para que la niña María Luz lave a ese hijo que le dejo, que seguramente será más generoso y noble que usted, como que tiene sangre de Sojo." ${ }^{4}$

Como es de observar en la descripción anterior se destacan los adjetivos empleados no solo por su valor semántico sino por el valor fónico de las vocales oscuras a, u, o que aparecen: profundos, dureza, implacable, cruel, azul. Por el contrario, cuando surgen las vocales claras, e, i, que aliviarían la tensión vocálica creada por el escritor, el valor semántico opaca esta claridad y anuncia un futuro desesperanzador: "los resplandores de un incendio diabólico".

También es pintado el envejecimiento prematuro y veloz de Juan Francisco, que es descrito con detalle y nuevamente con la adecuada selección adjetival realizada por el autor de la novela: "Dos surcos profundos le partían el entrecejo, imprimiéndole a su rostro una dureza implacable y cruel. Sus ojos, de azul desvanecido, parecían mirar por encima de los muros de la sala

43 Ibíd.

44 Op. cit., pág. 164. 
un punto lejano, algo que reflejaba en sus pupilas resplandores de un incendio diabólico." ${ }^{5}$ Destacan en esta adjetivación el vocablo inmisericorde que anuncia el futuro comportamiento del padre de María Luz, así como los sustantivos tragedia y catástrofe que son como otro anuncio de lo que está por suceder.

Los científicos del cerebro señalarían que el lóbulo prefrontal, que es el centro de la inteligencia y la voluntad, había dejado de funcionar y esto es lo que captaron los esclavos y lo explicita López Albújar: Juan Manuel “el día íntegro se lo había pasado, unas veces dando órdenes, otras, apurando entre veguero y veguero, grandes sorbos de café. Y todo esto en una apariencia de tranquilidad que, en vez de aquietar, causaba en su servidumbre un pavor inexplicable. Es que esas veinticuatro horas aquel hombre se había deshumanizado y todo lo que fluía en él tenía una tal radiación de dolor y fiereza que sobrecogía al que miraba." 46

La selección de vocablos así lo revela puesto que lo dice la referencia anterior, surge "un pavor inexplicable" y la "fiereza" era tal que "sobrecogía al que miraba". Aunque López Albújar es considerado por los estudiosos como un autor costumbrista, es en realidad un escritor que está emparentado en muchos aspectos con el romanticismo, en especial en la descripción que hace de la habitación y los objetos que se encuentran en ella

La misma habitación parecía estar con él al unísono hosquedad, silencio, pesadez, frialdad, penumbra, limitación, enigma... Por el polvo de los muebles semiseculares no había pasado aquel día una mano diligente. Del candelabro de cinco luces, solamente una ardía

45 Op. cit., pág. 61.

46 Op. cit., pág. 161. 
con llama vacilante, bastando apenas para ahuyentar los asaltos de la sombra, empeñada, al parecer, en cubrir piadosamente tanta desesperación y tristeza. Los retratos que pendían de las paredes pugnaban por descolgarse y huir. Unos de ellos. El más ampuloso de la barba, de aire señoril y gravedad muy española, parecía que todo el azul de sus ojos se le había trocado en un mandato imperativo, irresistible, que era necesario obedecer. Era uno de los abuelos paternos de este otro señor que tejía, seguramente, en el silencio de la noche, la urdimbre de una tragedia, comunicándole, poseído tal vez por la enormidad de lo que meditaba, algo de su adustez a las cosas. Y por obra de esa deshumanización, el hombre que estaba ahí semejaba una fiera acorralada, y la habitación, una guarida." ${ }^{\prime 4}$

Como hemos podido observar en las citas anteriores de Palma, en López Albújar el clímax de la novela es descrito desde el comienzo del capítulo titulado "El último jabón de la tina", donde se dibuja el callejón de la muerte que debe recorrer Pantaleón. López Albújar lo hace de una manera "ralentizada”, paso a paso: "Don Juan Francisco salió de su ensimismamiento, y volviendo los ojos al esclavo que, poseído por la soledad del momento, no se había atrevido a hablar (y) murmuró:

-iAh, estabas ahí!

-Sí, mi amo. Venía desile que no está listo.

-iTodo?

-Todito, mi amo Antuco, cumplí al pie e letra lo que su mersé manda-Dame la capa y el sombrero. ${ }^{48}$

El empleo de la cromatografía y de la sinestesia auditiva es evidente en la cita anterior, a través de las frases "pálido charco de luz y fría tinta de la noche".

47 Op. Cit., pág. 162.

48 López Albújar, op. Cit., pág. 162. 
Enseguida, y continuando la cita anterior, el autor de la novela escribe:

"Y una vez en posesión de las dos prendas, don Juan Francisco salió precedido del viejo mayordomo, el cual, farol en mano, comenzó a guiarle entre el laberinto del jardín y las callejuelas formadas por la arrumazón de los fardos y zurrones. Ni un chirrido, ni un graznido, ni un murmullo... Amo y esclavo avanzaban quedamente, como dos siluetas, que, perseguidas por un pálido charco de luz, trataran de disolverse en la fría tinta de la noche". ${ }^{9}$

El segundo paso del callejón continúa en el segundo patio en el que se describe el lugar de la acción y el diálogo entre los principales personajes de este episodio. "-Ya en el segundo patio no fue necesario el farol. El sangriento reflejo de los hornos de las tintas alumbraba lo suficiente para prescindir de toda luz. Don Juan Francisco avanzó hasta el fondo, donde un grupo de tres hombres esperaba, y dirigiéndose al que estaba en medio, díjole, con reconcentrada ira:

-Ya supondrás lo que voy a hacer contigo, inegro canalla, ingrato, desleal! -Si; lo que hace el cuchillo con la carne, señor.

-Algo mejor que eso. Ahorcarte, no. iEso quisieras! Ni garrote tampoco. Eso, para los caballeros.

-Cualquiera que sea la muerte que me dé usted la recibiré con resignación, como el pago merecido de una deuda que he contraído con usted.

-iNo balandronees, miserable! Mejor sería que te encomendaras a Dios. Tienes unos minutos para que los hagas.

-Ya lo he hecho, don Juan; todo el día he rezado. Yo soy un buen cristiano y sé que la oración consuela y purifica. Desde que se me engrilló y metió en el calabozo sabía lo que podía esperar."

49 Ibid.

50 Ibid. 
Finalmente, se establece el larguísimo diálogo entre José Manuel y Juan Francisco, en donde destaca la perspectiva diferente del amo y del esclavo, la dignidad de este último frente a la inmisericordia de Juan Francisco, y, nuevamente, al igual que en "La Emplazada", la cruel orden del poderoso frente a la situación inerme del esclavo: "Cárguenlo y llévenlo allá, he dicho... ${ }^{51}$, "gritó, dirigiéndose a los esclavos que lo tenían a este cogido por los brazos-

-iAllá, allá, a esa plataforma! Y tu Antuco, dirígelos como te he indicado ya." ${ }^{52}$

-iSúbanlo! isúbanlo! -repitió rabiosamente don Juan-. Que no tenga que decirlo otra vez. ${ }^{53}$

"Y los dos fornidos congos, el de la risa indomable y la copla canallesca y el otro, un mozo de herrería, cogiendo violentamente al infeliz por los brazos y las piernas, salvaron de unos cuantos trancos la rampa y se detuvieron sobre la plataforma que engolillaba a una de las enormes tinas de jabón, rugiente y humeante como un cráter voraz". ${ }^{54}$

Por último, y como queda demostrado a lo largo de este artículo, es evidente no solo la influencia que Palma ejerció en López Albújar sino la quasi adaptación de la tradición a una novela: de la tradición "La Emplazada" a la novela Matalaché.

51 Op. Cit., pág. 164.

52 Ibid.

53 Ibíd.

54 Ibíd. 


\section{BIBLIOGRAFIA}

Cuesta Abad, José Manuel. Teoría hermenéutica y literatura (el sujeto del texto. Barcelona, Visor, 1991+

Escajadillo, Tomás. ¿López Albújar: narrador o juez? Revista de Crítica Latinoamericana, año 36, $\mathrm{N}^{\circ} 72,2010$.

López Albújar, Enrique. Cuentos Andinos. Lima, Libertadores de América, 1983.

López Albújar, Enrique. Matalaché. Lima, Editorial Peisa, 1973.

López Albújar, Enrique. Nuevos Cuentos Andinos. Santiago de Chile, Ed. Ercilla, 1937.

Palma, Ricardo. Las tradiciones peruanas completas. Edición y prólogo de Edith Palma. Madrid, Aguilar, 1964.

Roll, Dietrich. En busca del texto: Teoría de la recepción literaria. México, UNAM, 1987.

Varios. Revistas del Instituto Ricardo Palma de la Universidad Ricardo Palma, 1997 a la fecha. 